\title{
Design and Cosimulation of Twelve-Pole Heteropolar Radial Hybrid Magnetic Bearing
}

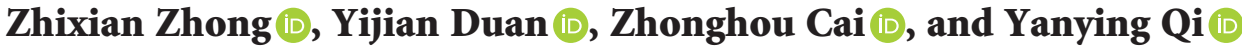 \\ College of Mechanical and Control Engineering, Guilin University of Technology, 541000 Guilin, China \\ Correspondence should be addressed to Zhixian Zhong; 2005zhzhx@163.com
}

Received 25 September 2020; Revised 23 February 2021; Accepted 29 March 2021; Published 22 April 2021

Academic Editor: Xunjie Gou

Copyright (c) 2021 Zhixian Zhong et al. This is an open access article distributed under the Creative Commons Attribution License, which permits unrestricted use, distribution, and reproduction in any medium, provided the original work is properly cited.

\begin{abstract}
This paper presents a twelve-pole heteropolar radial hybrid magnetic bearing (HRHMB) structure. Firstly, the structure and equivalent magnetic circuit (EMC) are designed. And the radial electromagnetic force characteristics are calculated by the EMC model. At the same time, the rationality of EMC model is verified by the finite-element method (FEM) of Magnet software. Then, the 2-D model of the twelve-pole HRHMB is established in Magnet software. The flux density variations of twelve-pole HRHMB and eight-pole HRHMB under different currents are compared by using the FEM. Finally, a method of Magnet-Simulink cosimulation is proposed to analyze the suspension characteristics of the twelve-pole HRHMB and compared with the eight-pole HRHMB. Thus, the effective combination of theoretical analysis, FEM analysis, and Magnet-Simulink cosimulation analysis is realized in the design of HRHMB. The results of Magnet-Simulink cosimulation show that the twelve-pole HRHMB has the advantages of low power consumption, small coupling, large construction dynamic stiffness, and better suspension characteristics than the eight-pole HRHMB.
\end{abstract}

\section{Introduction}

Hybrid magnetic bearing (HMB) combines the characteristics of the active magnetic bearing and the passive magnetic bearing. In the HMB, the permanent magnet is used instead of the electromagnetic coil to generate the required bias flux, while the electromagnetic coil is only responsible for generating the control flux. Therefore, the power loss and volume of the magnetic bearing are greatly reduced [1-5]. Based on the above characteristics, HMB has irreplaceable advantages in the field of small size and low power consumption. Hence, HMB has broad application prospects in many industrial occasions such as flywheel energy storage system (FESS) [6], artificial heart [7], high-speed blower [8], molecular vacuum pump [9], and so on [10].

In domestic and foreign research, the $\mathrm{HMB}$ can be roughly divided into two categories, namely, homopolar hybrid magnetic bearing and heteropolar hybrid magnetic bearing $[11,12]$. Among them, the heteropolar radial hybrid magnetic bearing has the advantages of relatively short axial length, less magnetic flux leakage, and lower power consumption than the homopolar radial hybrid magnetic bearing. Therefore, it also has been widely concerned by many scholars $[13,14]$ proposing a structure of HRHMB. In this structure, the four control magnetic poles of the stator and the four permanent magnetic poles inlaid with permanent magnets are arranged alternately to form the NSNS magnetic pole arrangement sequence. In [15], the parameter design method of the structure is derived, and the prototype of HRHMB is manufactured by using this method [14]. The simulation and experimental results of the prototype show that the HRHMB structure designed by the parameter design method has excellent suspension performance. In order to reduce power consumption and improve the space utilization of the entire system, a novel eight-pole heteropolar radial-axial hybrid magnetic bearing is present in [16]. The parameters of the structure are optimized, and the structure prototype is made. The results of experiment and simulation show that the maximum bearing capacity of HMB in the radial and axial directions is $82.6 \%$ and $81 \%$ of the theoretical value, respectively. Zhu et al. [17] proposed a novel of HRHMB with low power loss for the FESS, and its structural 
optimization design was carried out based on the equivalent magnetic circuit model. Then after the 3D FEM, the simulation results show that the maximum control current in the electromagnetic coil can be reduced to $40 \%$ of the original structure by optimizing the design. In [18], a 3-DOF electromagnetic bearing with annular radial control coil is proposed. This structure reduces the copper loss of the electromagnetic bearing structure by using annular coil, and the weak cross coupling effect of 3-DOF electromagnetic bearing is proved by 3-D FEM. Sun et al. [19] proposed a new decoupling control scheme for a 4-DOF PMBAMB in a direct-driven spindle system based on the neural network inverse and 2-degree-of-freedom internal model control method. And the experimental results demonstrate the effectiveness of the proposed control scheme. In [20], a threedegree-of-freedom hybrid magnetic bearing is optimized as an example. First, a comprehensive sensitivity analysis is carried out to show the relationship between the parameters and optimization objectives in detail. Second, a cross-factor variance analysis is considered due to the possibility of parameter interaction. And then, a hierarchical multiobjective optimization structure is used with the Kriging model and the nondominated Sorting Genetic Algorithm 2. Finally, the simulation results verify the validity of the proposed method.

Most of the structures of HRHMB are based on the eightpole HRHMB in $[14,21]$. In this structure, the block permanent magnet is embedded into the stator yoke. Therefore, the bias flux provided by the permanent magnet is uniformly distributed on the stator surface, which realizes the radial 2DOF suspension of the rotor core. However, when the air gap flux of the right two magnetic poles in the horizontal direction increases, the air gap flux of the left two magnetic poles in the vertical direction also increases. Hence, there is a left bearing capacity in the structure, and it weakens the right bearing capacity. This will increase the power consumption of the magnetic bearing and reduce the suspension performance of the electromagnetic bearing. In order to solve this problem, this paper proposes a structure of twelve-pole HRHMB. By increasing the number of 8 control magnetic poles to 12 , the coupling between the bias flux and the control magnetic field is reduced, and the suspension performance of the electromagnetic bearing is enhanced.

At present, many scholars generally carry out theoretical research on $\mathrm{HRHMB}$, and an experimental platform is built to monitor the changes in parameters such as rotor displacement and coil current of HRHMB. But the experiment of using the above method is difficult, and the cost is high. Besides, data observation is not flexible enough, and it is difficult to truly observe the influence of the HRHMB structural parameters optimization on the actual control [22-27]. In order to solve this problem, this paper proposes a method of Magnet-Simulink cosimulation. First, the HRHMB model is imported into Simulink. Then, through the real-time data exchange between Magnet and MATLAB software, the current, voltage, electromagnetic force, speed, displacement, and other parameters in HRHMB can be monitored in real time. Through this method, theoretical analysis, FEM analysis, and control simulation analysis can be effectively combined into the structural optimization design. Taking the control strategy of the system into consideration can make the structural optimization design of HRHMB more accurate and practical. At the same time, the cost of the experiment is reduced, and the efficiency of the HRHMB structure design is improved. Thus, the suspension characteristics and power consumption of the HRHMB system can be analyzed more intuitively [28].

\section{Structure and Model}

The structure of the twelve-pole HRHMB is shown in Figure 1. The twelve-pole HRHMB is composed of radial stator, radial control winding, rotor, and permanent magnet. In order to reduce hysteresis and eddy current loss, the radial stator core and rotor core are made of silicon steel sheets. In the stator, the twelve control magnetic poles with the same number of turns are arranged symmetrically, which forms an alternating arrangement of NS poles. Among them $a_{n}$ and $c_{n}(n=1,2,3)$ are the upper and lower magnetic poles in the vertical direction of the stator. $b_{n}$ and $d_{n}(n=1,2,3)$ are, respectively, the left and right control magnetic poles in the horizontal. In addition, the four block permanent magnets are uniformly embedded in the stator yoke, which provide a bias flux for the structure.

The flux density distribution of the twelve-pole HRHMB is shown in Figure 2. The bias flux generated by the permanent magnet passes through the permanent magnet pole, the air gap, the rotor, the control magnetic pole, and the stator yoke, which forms a closed loop. The control flux generated by the control winding passes through the stator yoke, the control magnetic pole, the air gap, and the rotor, which forms a closed loop. Due to the high magnetoresistance of permanent magnets, the control flux cannot pass through permanent magnetic poles. Therefore, the demagnetization of permanent magnets is avoided.

When the rotor is stably suspended in the equilibrium position, the bias flux flows between two adjacent magnetic poles. Therefore, four equal bias fluxes are formed on the surface of the rotor, and the resultant force received by the rotor is zero. If the rotor is subjected to a vertical downward impact force, it will move downward from the central position. As a result, the air gap between the lower magnetic pole and the rotor in the stator is reduced, and the bias flux density increases in the air gap. At this time, due to the unbalance of the bias flux, the direction of the resultant force is downward, and the position of the rotor drops. In order to restore the rotor to the equilibrium state, a certain amount of current must be applied to the magnetic pole on the upper side of the stator. At this point, the control flux generated by the control magnetic pole flows from the middle $\mathrm{N}$ pole of the upper pole to the $S$ pole on both sides. And then the control flux flows back to the $\mathrm{N}$ pole from the $\mathrm{S}$ pole to form a closed loop so that the rotor is subjected to a vertical upward suction. Under the current regulation of the controller, the rotor is finally suspended in the equilibrium position. 


\section{Analysis of EMC}

In Figure 3(a), $F_{m}$ is the magnetomotive force provided by the permanent magnet. $H_{c}$ is the coercivity of the permanent magnet. $L_{m}$ is the radial thickness of the permanent magnet. Thus, it can be approximated as

$$
F_{m}=H_{c} L_{m} .
$$

The magnetoresistance of a permanent magnet can be calculated by

$$
R_{m}=\frac{L_{m}}{\mu_{m} S_{m}},
$$

where $R_{m}$ is the permanent magnet reluctance, $\mu_{m}$ is the permeability of permanent magnetic materials, and $S_{m}$ is the area of the stator pole.

The bias flux in the branches produced by the permanent magnet is defined as $\phi_{k}(k=1,2,3,4,5,6,7,8,9,10,11,12)$. Therefore, the bias flux of each branch can be calculated by

$$
\begin{aligned}
& \int \phi_{1}=\frac{R_{12}\left(R_{3}+R_{2}\right) F_{m}}{R_{1} R_{2} R_{3}+R_{1} R_{2} R_{12}+R_{1} R_{2} R_{m}+R_{2} R_{3} R_{12}+R_{2} R_{12} R_{m}+R_{1} R_{3} R_{12}+R_{1} R_{3} R_{m}+R_{3} R_{12} R_{m}}, \\
& \phi_{2}=\frac{R_{3}\left(R_{1}+R_{12}\right) F_{m}}{R_{1} R_{2} R_{3}+R_{1} R_{2} R_{12}+R_{1} R_{2} R_{m}+R_{2} R_{3} R_{12}+R_{2} R_{12} R_{m}+R_{1} R_{3} R_{12}+R_{1} R_{3} R_{m}+R_{3} R_{12} R_{m}}, \\
& \phi_{3}=\frac{R_{2}\left(R_{1}+R_{12}\right) F_{m}}{R_{1} R_{2} R_{3}+R_{1} R_{2} R_{12}+R_{1} R_{2} R_{m}+R_{2} R_{3} R_{12}+R_{2} R_{12} R_{m}+R_{1} R_{3} R_{12}+R_{1} R_{3} R_{m}+R_{3} R_{12} R_{m}}, \\
& \phi_{4}=\frac{R_{3}\left(R_{5}+R_{6}\right) F_{m}}{R_{3} R_{4} R_{5}+R_{4} R_{5} R_{6}+R_{4} R_{5} R_{m}+R_{3} R_{4} R_{6}+R_{4} R_{6} R_{m}+R_{3} R_{5} R_{6}+R_{3} R_{5} R_{m}+R_{4} R_{7} R_{m}}, \\
& \phi_{5}=\frac{R_{6}\left(R_{3}+R_{4}\right) F_{m}}{R_{3} R_{4} R_{5}+R_{4} R_{5} R_{6}+R_{4} R_{5} R_{m}+R_{3} R_{4} R_{6}+R_{4} R_{6} R_{m}+R_{3} R_{5} R_{6}+R_{3} R_{5} R_{m}+R_{4} R_{7} R_{m}}, \\
& \phi_{6}=\frac{R_{5}\left(R_{3}+R_{4}\right) F_{m}}{R_{3} R_{4} R_{5}+R_{4} R_{5} R_{6}+R_{4} R_{5} R_{m}+R_{3} R_{4} R_{6}+R_{4} R_{6} R_{m}+R_{3} R_{5} R_{6}+R_{3} R_{5} R_{m}+R_{4} R_{7} R_{m}}, \\
& \phi_{7}=\frac{R_{6}\left(R_{4}+R_{5}\right) F_{m}}{R_{5} R_{6} R_{7}+R_{4} R_{5} R_{6}+R_{5} R_{6} R_{m}+R_{4} R_{6} R_{7}+R_{4} R_{6} R_{m}+R_{5} R_{7} R_{12}+R_{5} R_{7} R_{m}+R_{4} R_{7} R_{m}}, \\
& \phi_{8}=\frac{R_{9}\left(R_{6}+R_{7}\right) F_{m}}{R_{7} R_{8} R_{9}+R_{6} R_{7} R_{8}+R_{7} R_{8} R_{m}+R_{6} R_{8} R_{9}+R_{6} R_{8} R_{m}+R_{6} R_{7} R_{9}+R_{7} R_{9} R_{m}+R_{6} R_{9} R_{m}}, \\
& \phi_{9}=\frac{R_{8}\left(R_{6}+R_{7}\right) F_{m}}{R_{7} R_{8} R_{9}+R_{6} R_{7} R_{8}+R_{7} R_{8} R_{m}+R_{6} R_{8} R_{9}+R_{6} R_{8} R_{m}+R_{6} R_{7} R_{9}+R_{7} R_{9} R_{m}+R_{6} R_{9} R_{m}} \\
& \phi_{10}=\frac{R_{11}\left(R_{9}+R_{12}\right) F_{m}}{R_{9} R_{10} R_{11}+R_{10} R_{11} R_{12}+R_{10} R_{11} R_{m}+R_{9} R_{10} R_{12}+R_{10} R_{12} R_{m}+R_{9} R_{11} R_{12}+R_{9} R_{11} R_{m}+R_{9} R_{12} R_{m}}, \\
& \phi_{11}=\frac{R_{12}\left(R_{9}+R_{10}\right) F_{m}}{R_{9} R_{10} R_{11}+R_{10} R_{11} R_{12}+R_{10} R_{11} R_{m}+R_{9} R_{10} R_{12}+R_{10} R_{12} R_{m}+R_{9} R_{11} R_{12}+R_{9} R_{11} R_{m}+R_{9} R_{12} R_{m}} \\
& \phi_{12}=\frac{R_{1}\left(R_{2}+R_{3}\right) F_{m}}{R_{1} R_{2} R_{3}+R_{1} R_{2} R_{12}+R_{1} R_{2} R_{m}+R_{2} R_{3} R_{12}+R_{2} R_{12} R_{m}+R_{1} R_{3} R_{12}+R_{1} R_{3} R_{m}+R_{3} R_{12} R_{m}} .
\end{aligned}
$$

In Figure 3(b), $N_{k} I_{k}(k=1,2,3,4,5,6,7,8,9,10,11,12)$ is the magnetomotive force generated by the control coil. 
$\phi a_{k}, \phi b_{k}, \phi c_{k}$, and $\phi d_{k}$ are the control flux of each branch in the control magnetic circuit. The control magnetic flux of each branch of the magnetic field can be calculated by

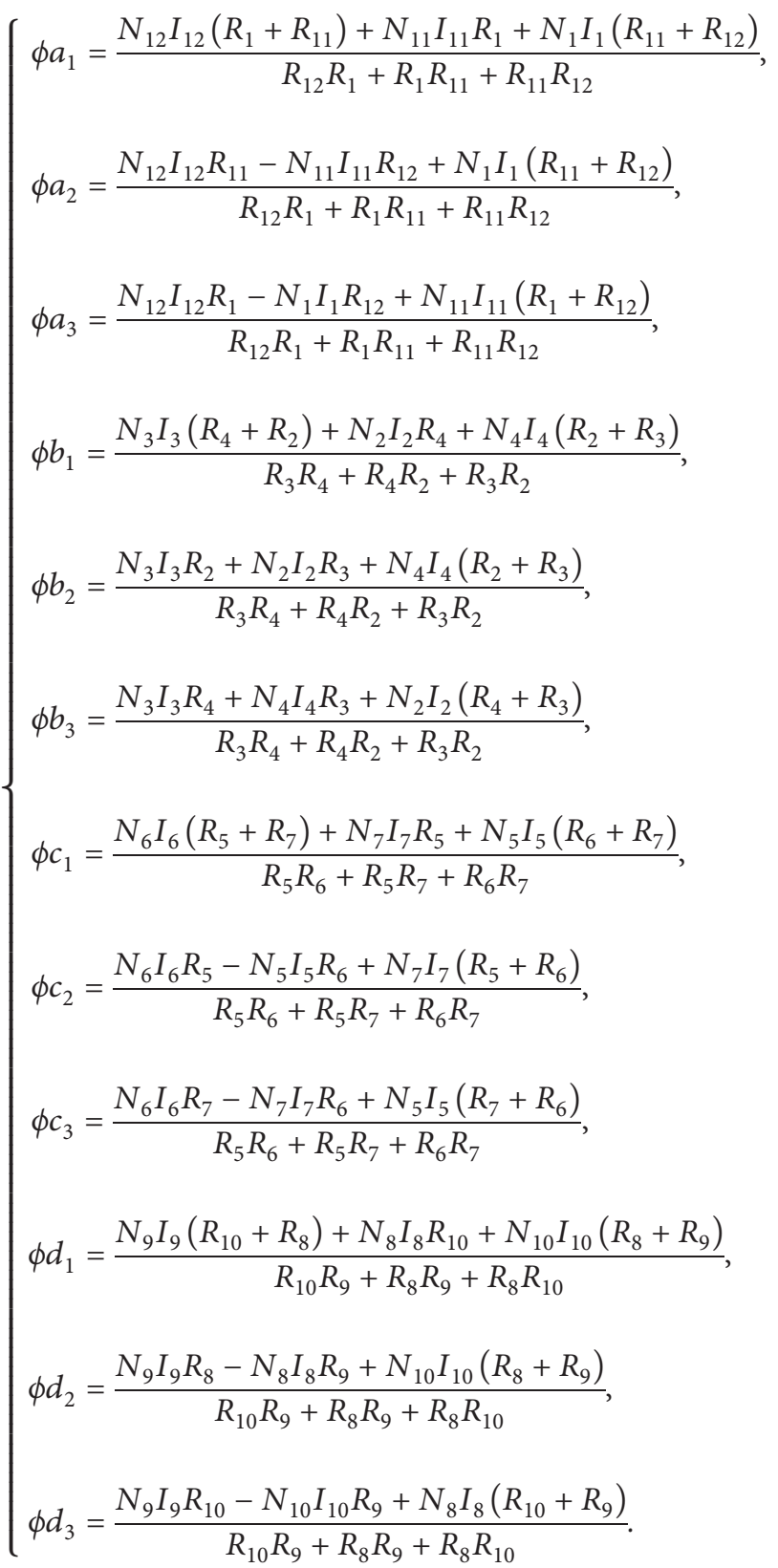

Then the total magnetic flux of the magnetic field in each air gap can be expressed as

$$
\left\{\begin{array}{l}
\phi x_{1}=\phi d_{1}-\phi_{9}+\left(\phi d_{2}+\phi_{10}+\phi d_{3}+\phi_{8}\right) \times \cos 30^{\circ}+\left(\phi_{11}+\phi c_{2}+\phi \mathrm{a}_{3}+\phi_{7}\right) \times \cos 60^{\circ}, \\
\phi x_{2}=\phi b_{1}-\phi_{3}+\left(\phi b_{2}+\phi_{2}+\phi b_{3}+\phi_{4}\right) \times \cos 30^{\circ}+\left(\phi_{1}+\phi \mathrm{a}_{2}+\phi c_{3}+\phi_{5}\right) \times \cos 60^{\circ}, \\
\phi y_{1}=\phi a_{1}-\phi_{12}+\left(\phi a_{2}+\phi_{1}+\phi a_{3}+\phi_{11}\right) \times \cos 30^{\circ}+\left(\phi_{2}+\phi \mathrm{b}_{3}+\phi \mathrm{d}_{2}+\phi 10\right) \times \cos 60^{\circ}, \\
\phi y_{2}=\phi c_{1}-\phi_{6}+\left(\phi c_{2}+\phi_{7}+\phi c_{3}+\phi_{5}\right) \times \cos 30^{\circ}+\left(\phi_{4}+\phi \mathrm{b}_{2}+\phi \mathrm{d}_{3}+\phi_{8}\right) \times \cos 60^{\circ},
\end{array}\right.
$$




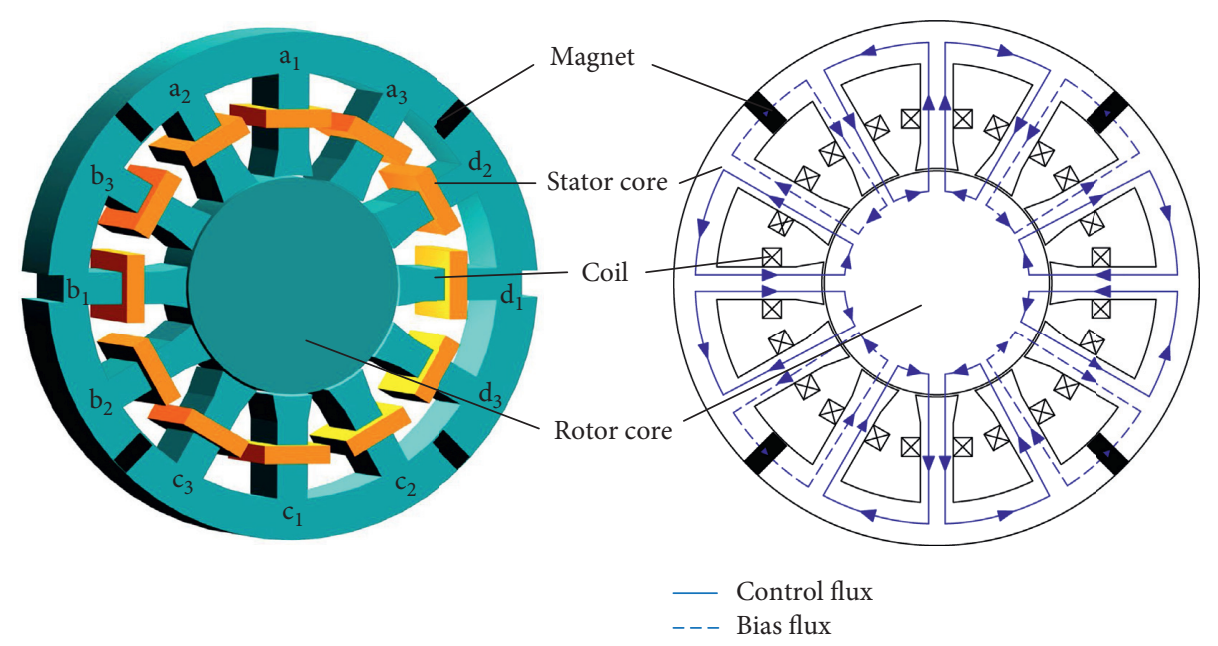

FIGURE 1: Structure for the twelve-pole HRHMB.

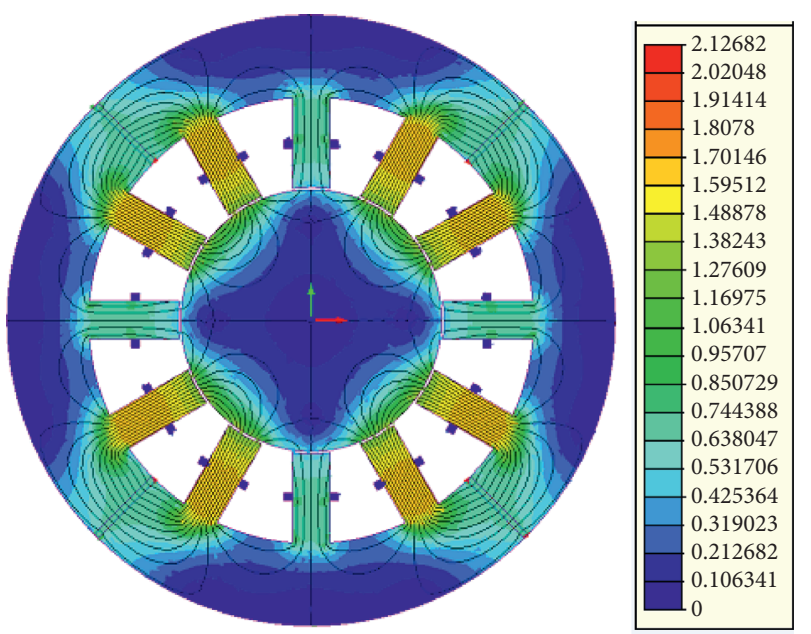

FIgURE 2: The flux density distribution of the twelve-pole HRHMB.

where $\phi x_{1}, \phi x_{2}, \phi y_{1}$, and $\phi y_{2}$ are the magnetic flux passing through the air gap along the corresponding direction. In addition, the positive direction of the coordinate axis is defined as the positive direction of the force, and the positive direction of the current is defined as the direction that generates the positive force. According to Maxwell's equation, $F_{x}$ and $F_{y}$ can be calculated by

$$
\left\{\begin{array}{l}
F_{x}=\frac{\left[\left(\phi x_{1}\right)^{2}-\left(\phi x_{2}\right)^{2}\right]}{2 \mu_{0} s_{k}} \\
F_{y}=\frac{\left[\left(\phi y_{1}\right)^{2}-\left(\phi y_{2}\right)^{2}\right]}{2 \mu_{0} s_{k}}
\end{array}\right.
$$

where $F_{x}$ is the resultant force of electromagnetic force in the horizontal direction and $F_{y}$ is the resultant force of electromagnetic force in the vertical direction. The cross-sectional area of the air gap corresponding to a single magnetic pole is $s_{k}$.

In order to verify the accuracy of EMC, it was compared with the FEM results. The main parameters of the twelve- pole HRHMB are listed in Table 1. Then, the comparison of the FEM and the radial force characteristics predicted by the EMC model is shown in Figures 4(a)-4(d). And the other magnetic pole currents are all $2 \mathrm{~A}$, when the current in the corresponding magnetic pole changes.

It can be seen from Figures 4(a)-4(d) that the radial electromagnetic force of the twelve-pole HRHMB is linearly related to the control current. And it is also proved that the ratio coefficient of current to electromagnetic force calculated by the EMC method is close to the FEM. When the control current is $5 \mathrm{~A}$, the maximum horizontal radial electromagnetic force is $87.8 \mathrm{~N}$, and the maximum vertical radial electromagnetic force is 36 times of the rotor core weight. Therefore, it is sufficient to complete the control of the twelve-pole HRHMB.

\section{Comparison of Coupling Characteristics}

In order to analyze the coupling of the twelve-pole HRHMB, first, the twelve-pole HRHMB model is established. Then the change of the flux density on the rotor surface is analyzed on 


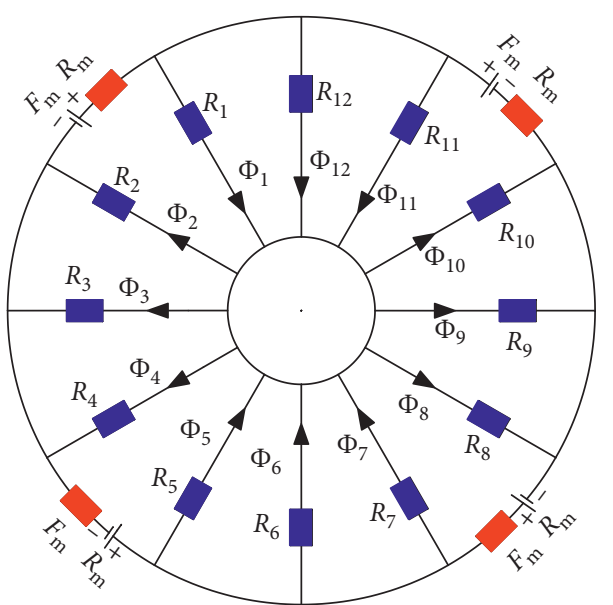

(a)

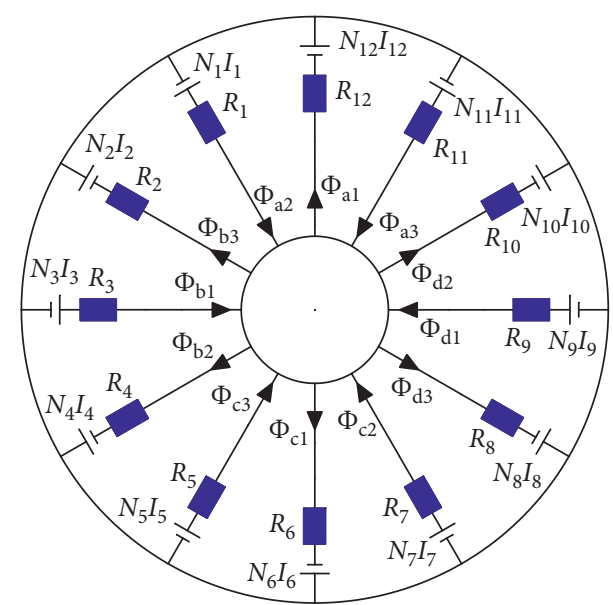

(b)

FIgure 3: EMC model. (a) Bias flux paths. (b) Control flux paths.

TABLE 1: Main parameters of twelve-pole HRHMB.

\begin{tabular}{lcc}
\hline Parameter & Description & Value \\
\hline$D_{\text {so }}$ & Outer diameter of the stator $(\mathrm{mm})$ & 112 \\
$D_{\text {ro }}$ & Outer diameter of the rotor $(\mathrm{mm})$ & 48 \\
$L$ & Length of magnetic bearing $(\mathrm{mm})$ & 21 \\
$g_{0}$ & Length of air gap $(\mathrm{mm})$ & 0.5 \\
$L_{m}$ & Thickness of PM $(\mathrm{mm})$ & 1 \\
$S_{m}$ & Area of PM $\left(\mathrm{mm}^{2}\right)$ & 310.8 \\
$N$ & Turn of control coil & 70 \\
$i_{x} / i_{y}$ & Maximum control current $(A)$ & 5 \\
$H_{c}$ & Coercivity $(\mathrm{KA} / \mathrm{m})$ & 827 \\
\hline
\end{tabular}

the Magnet software under different currents. Finally, the simulation results of twelve-pole HRHMB and eight-pole HRHMB are compared.

The eight-pole HRHMB structure in literature [13] is shown in Figure 5, which is the common structure of HMB. The eight-pole HRHMB is formed by inserting a permanent magnet into the yoke of an eight-pole active magnetic bearing. Among them $a_{k}$ and $c_{k}(k=1,2)$ are the upper and lower magnetic poles in the vertical direction of the stator. $b_{k}$ and $d_{k}$ are, respectively, the left and right control magnetic poles in the horizontal. Then, the radial suspension of the rotor core is realized by superimposing the control flux and the bias flux. But it can be seen from Figure 6 that when the air gap flux of the $d_{1}$ and $d_{2}$ poles increases, the air gap flux of the $a_{2}$ and $c_{1}$ poles also increases. Therefore, the unbalanced force is generated, and horizontal ability is weakened. At the same time, the excitation power of magnetic bearing is increased, and the suspension performance of magnetic bearing is reduced.

It can be seen from Figure 77(a) that when the current of $a_{k}$ and $c_{k}(k=1,2)$ changes from $2 \mathrm{~A}$ to $5 \mathrm{~A}$, the total difference of flux density in the air gap below $b_{k}$ and $d_{k}(k=1$, 2) is $\Delta B_{1}=0.1845 \mathrm{~T}$ and $\Delta B_{2}=0.08 \mathrm{~T}$, which is about 4.44 times and 1.92 times of $\Delta B_{1}$ and $\Delta B_{2}$ in Figure $7(\mathrm{~b})$.

As shown in Figures $7(\mathrm{c})$ and $7(\mathrm{~d})$, the current of the magnetic pole controlling the horizontal movement of the rotor between the twelve-pole $\mathrm{HRHMB}$ and the eight-pole HRHMB changes from $2 \mathrm{~A}$ to $5 \mathrm{~A} . \Delta B_{1}=\Delta B_{2}=0.0415 \mathrm{~T}$ in Figure $7(\mathrm{~d})$, which is 0.5 and 0.2 times of $\Delta B_{1}$ and $\Delta B_{2}$ in Figure 7(c), respectively.

In summary, the coupling of the twelve-pole HRHMB is smaller than that of the eight-pole HRHMB, and the current and flux density increment have a better linearity.

\section{Cosimulation}

As shown in Figure 8, the twelve-pole HRHMB model is established in the Magnet software and imported into Simulink. Then the PID control block diagram of the HRHMB system is established [29]. The current source of HRHMB corresponds to the input and output ports of the Magnet-Simulink plug-in. Besides, the output ports of the Magnet-Simulink plug-in add rotor displacement, coil electromagnetic force, rotor speed, and other parameters. The vertical and horizontal loads are $2.4 \mathrm{~N}$ (the gravity of the rotor model) and $0 \mathrm{~N}$ (the external force on the horizontal direction of the rotor is 0). After parameter tuning, the vertical PID controller parameters of the twelve-pole HRHMB are $K_{\mathrm{P}}=150800, K_{\mathrm{I}}=0.001$, and $K_{\mathrm{D}}=200$, and the horizontal PID controller parameters of the twelve-pole HRHMB are $K_{\mathrm{P}}=125000, K_{\mathrm{I}}=0.001$, and $K_{\mathrm{D}}=100$. At the same time, the vertical PID controller parameters of the 


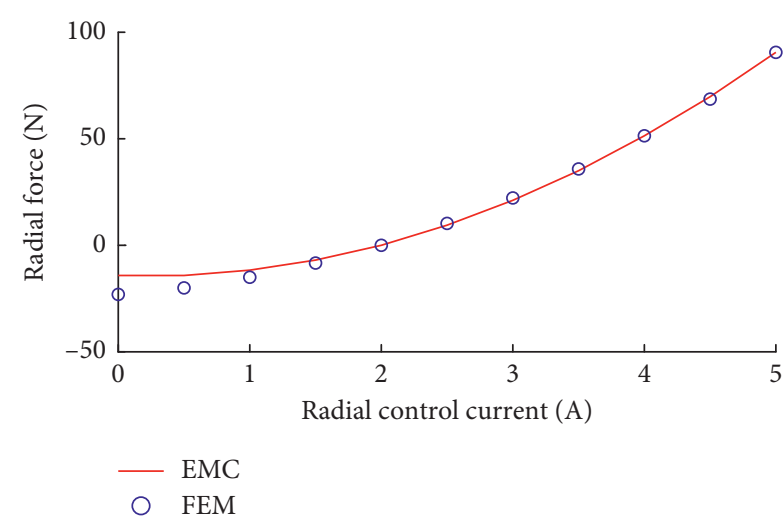

(a)

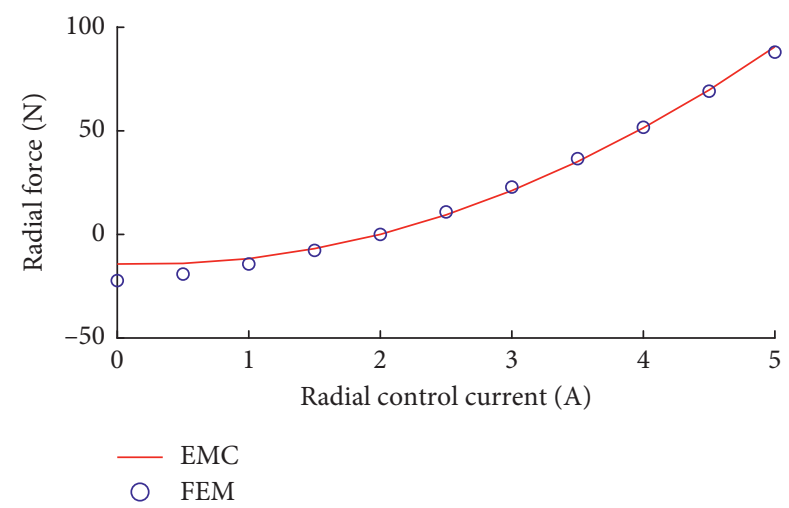

(c)

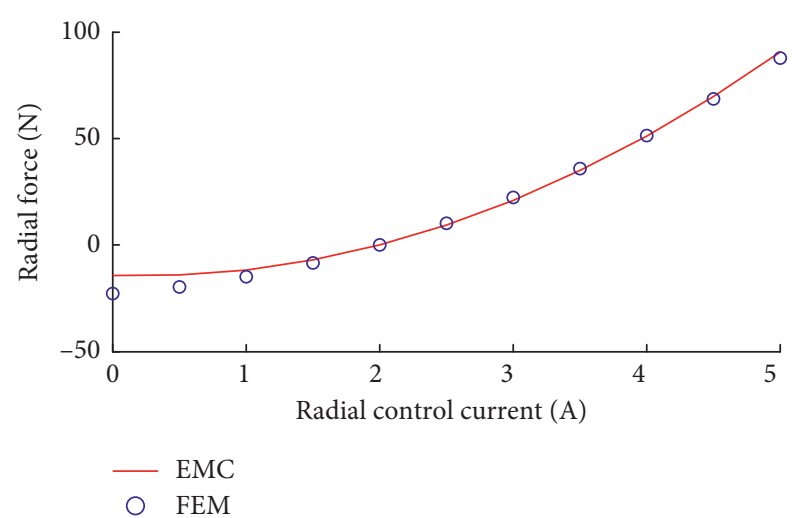

(b)

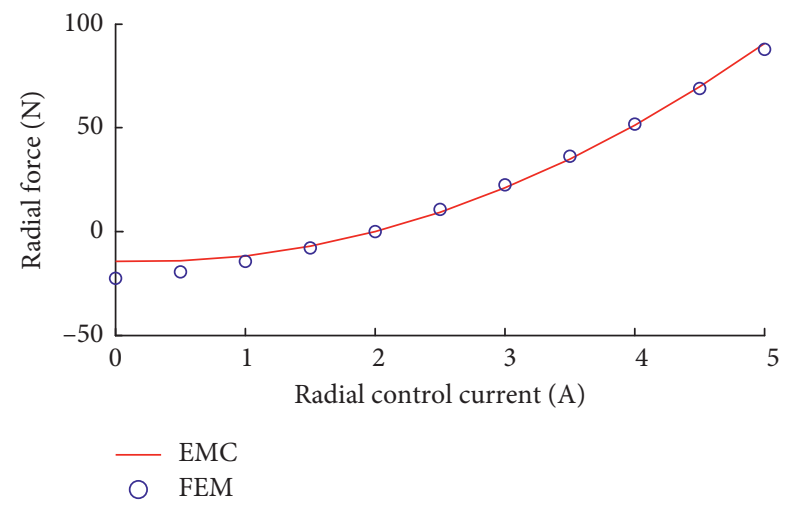

(d)

FIgURE 4: Force-current characteristics of the twelve-pole HRHMB. The characteristics of the stator's (a) upper and (b) lower magnetic pole current and vertical electromagnetic force. The characteristics of the stator's (c) right and (d) left magnetic pole current and horizontal electromagnetic force.

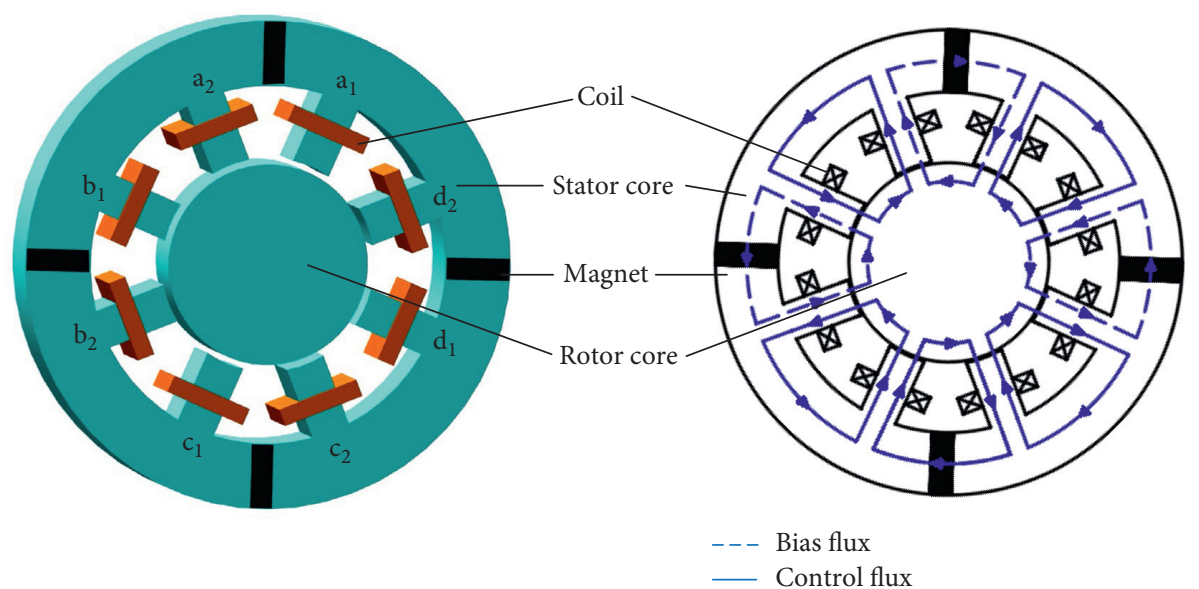

Figure 5: Structure for the eight-pole HRHMB. 


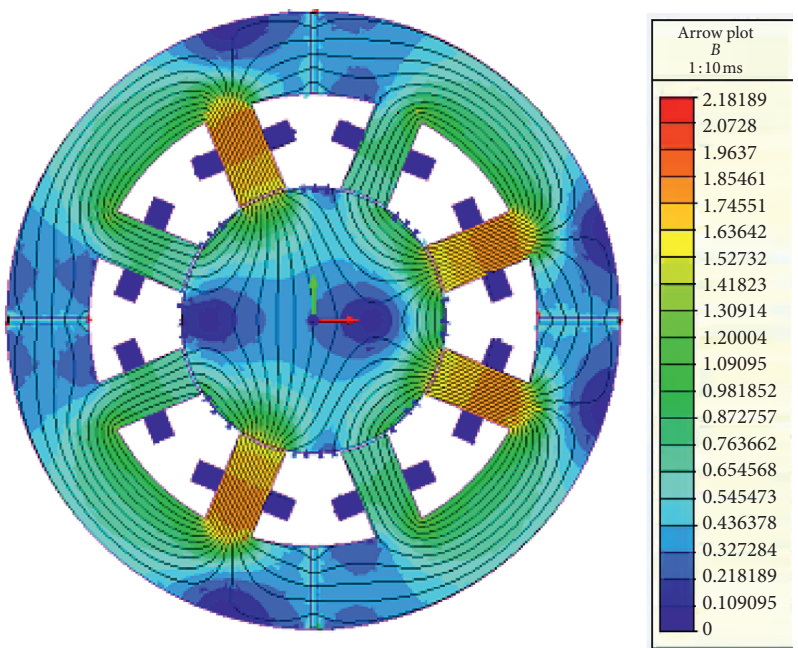

FIgURE 6: The flux density distribution of the eight-pole HRHMB.
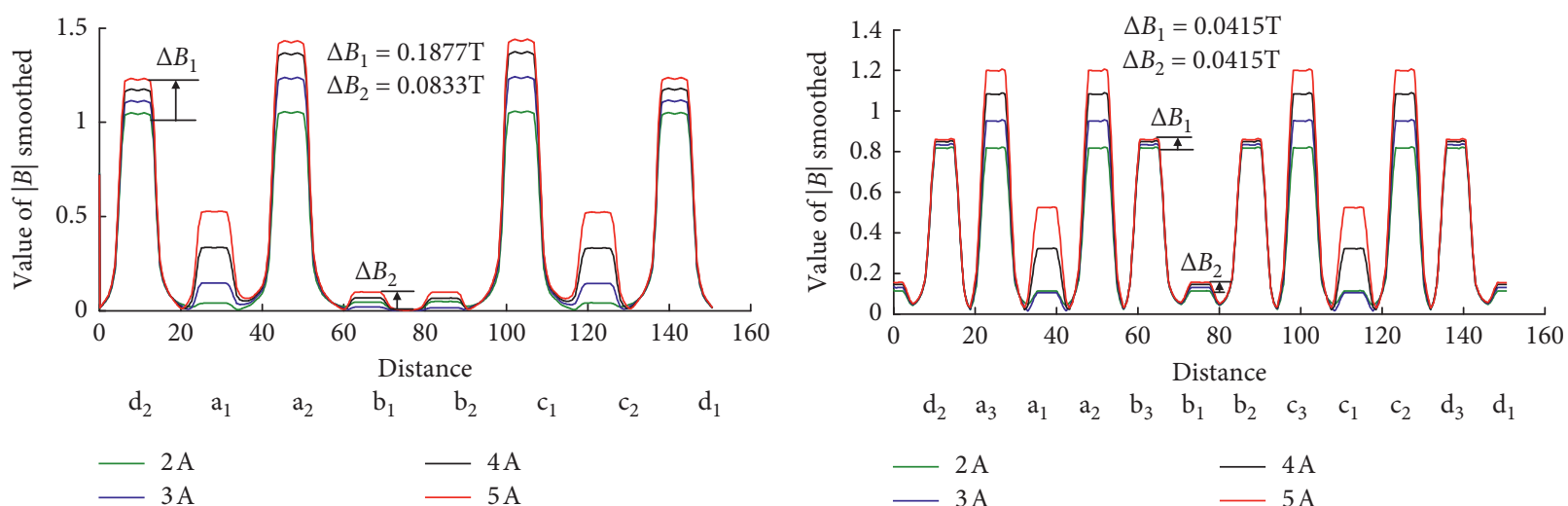

(a)

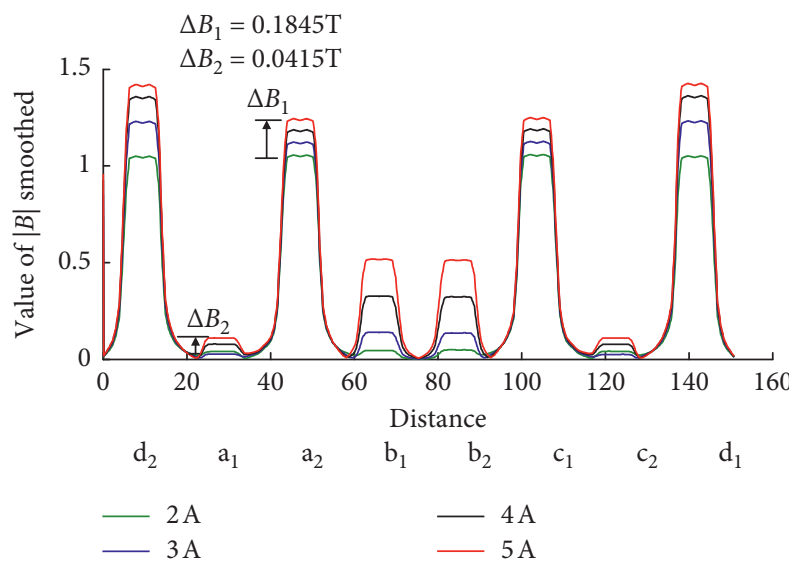

(c) (b)
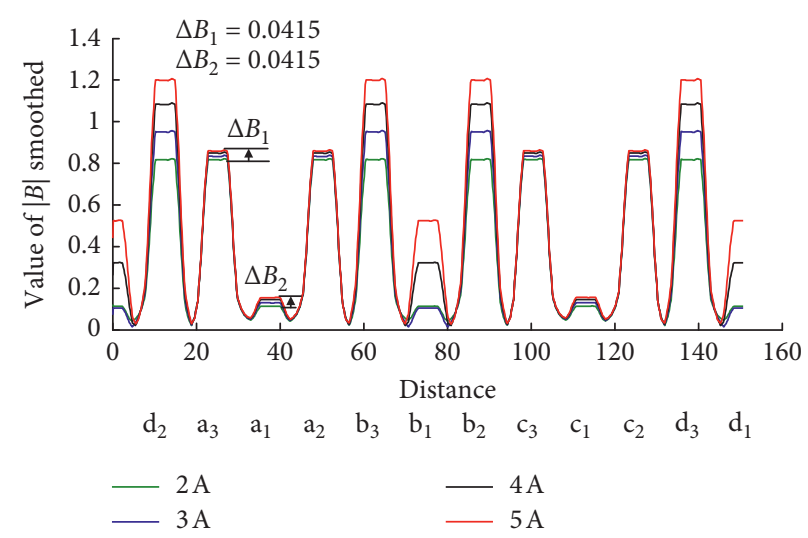

(d)

FIGURE 7: Distribution of air gap flux density with different control currents. Change of magnetic pole current of (a) the eight-pole HRHMB and (b) the twelve-pole HRHMB in the vertical direction. Change of magnetic pole current of (c) the eight-pole HRHMB and (d) the twelvepole HRHMB in the horizontal direction.

eight-pole HRHMB are $K_{\mathrm{P}}=205000, K_{\mathrm{I}}=0.001$, and $K_{\mathrm{D}}=12$, and the horizontal PID controller parameters of the eight-pole HRHMB are $K_{\mathrm{P}}=60000, K_{\mathrm{I}}=0.001$, and $K_{\mathrm{D}}=850$.
5.1. Comparison of Suspension Simulation. The radial displacement response of the twelve-pole HRHMB system and the eight-pole HRHMB system is shown in Figures 9(a)9(d). The oscillation time of the twelve-pole HRHMB system 


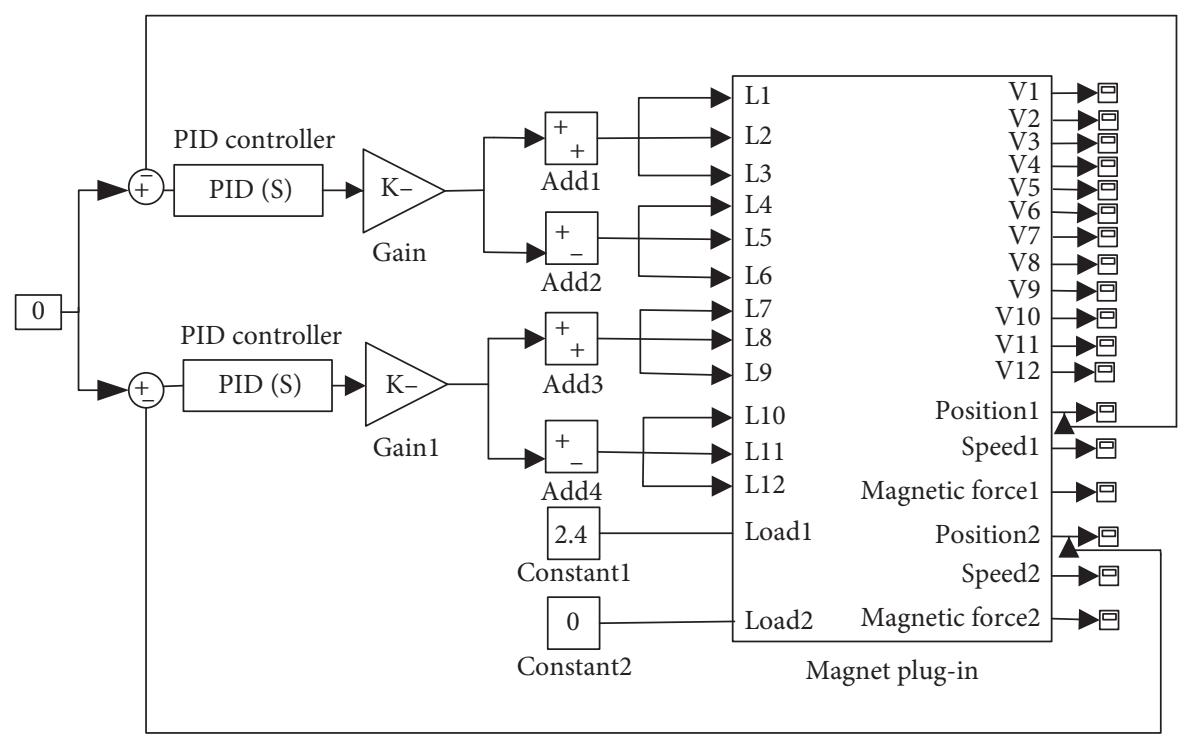

(a)

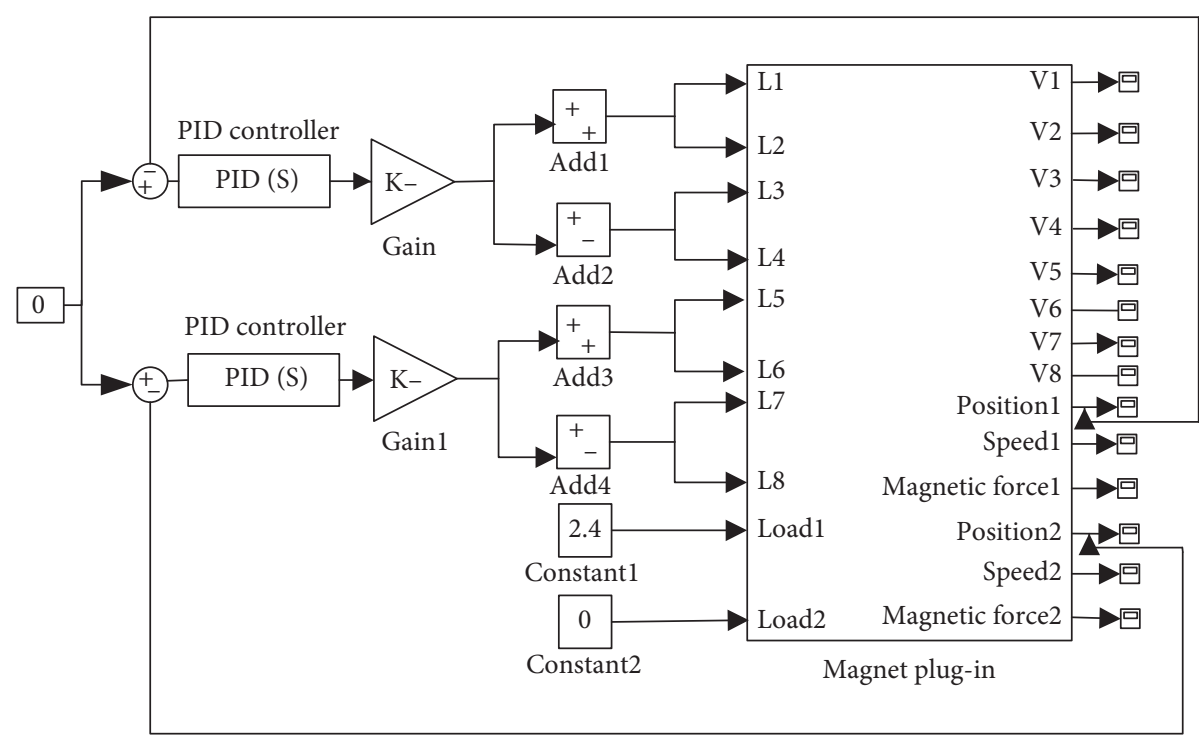

(b)

FIgURE 8: PID control block diagram of HRHMB system Magnet-Simulink cosimulation. (a) The twelve-pole HRHMB system. (b) The eight-pole HRHMB system.

in both vertical and horizontal directions is between 0 and $0.015 \mathrm{~s}$. In the oscillation stage, the maximum overshoot of the rotor in two directions is about $1.87 \times 10^{-6} \mathrm{~m}$ and $1.5 \times 10^{-6} \mathrm{~m}$, respectively. However, when the current is applied to the coil, the unbalanced force weakens the horizontal main bearing capacity and seriously affects the suspension characteristics. Therefore, the fluctuation time of the rotor in the horizontal and vertical directions is between $0-0.1 \mathrm{~s}$ and $0-0.2 \mathrm{~s}$, respectively. During the oscillation stage, the maximum overshoot in the horizontal and vertical directions of the rotor is about 16.04 and 33.3 times of the twelve-pole HRHMB system, respectively. According to the simulation results, the twelve-pole HRHMB system has better dynamic performance and suspension characteristics than the eight-pole HRHMB system. The flux density distribution of the stable suspension twelve-pole HRHMB system and the stable suspension eight-pole HRHMB system are shown in Figures 10(a)and 10(b). Because the total number of turns of the two HRHMB winding coils is the same, there is an unbalanced force in the eight-pole HRHMB. So the twelve-pole HRHMB flux density is higher than the eight-pole HRHMB flux density. At the same time, twelve-pole HRHMB is less prone to magnetic saturation than eight-pole HRHMB. 


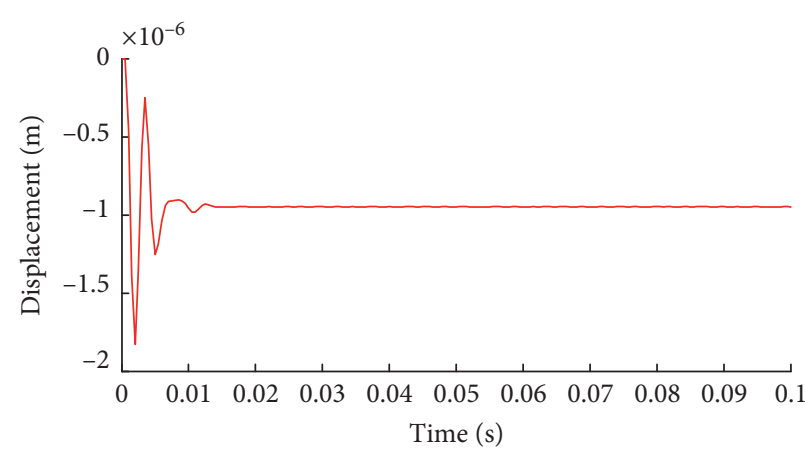

(a)

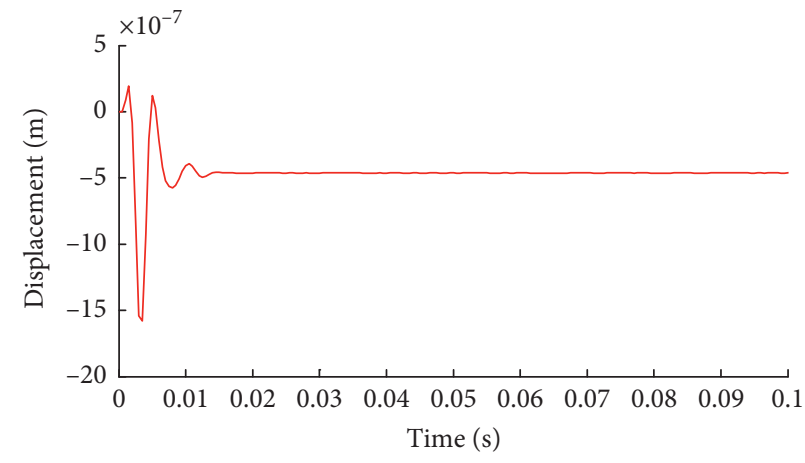

(c)

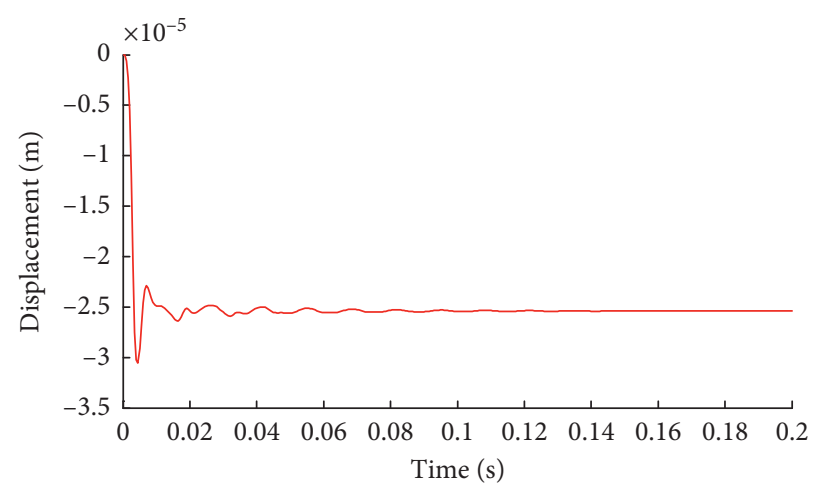

(b)

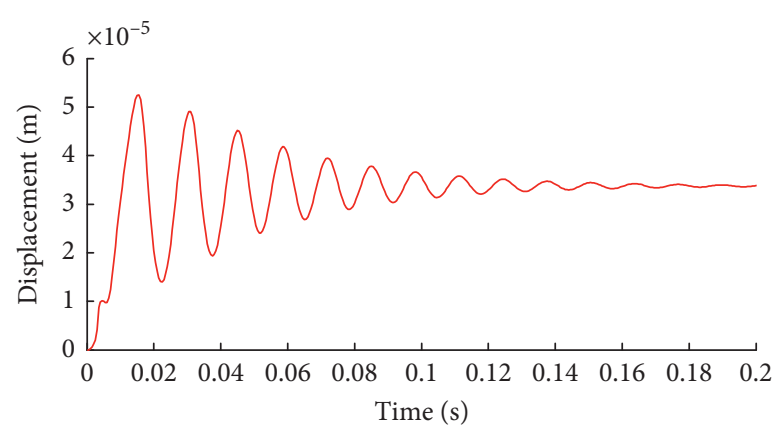

(d)

FIGURE 9: Radial displacement response of HRHMB system. The vertical displacement response of (a) the twelve-pole HRHMB system and (b) the eight-pole HRHMB system. The horizontal displacement response of (c) the twelve-pole HRHMB system and (d) the eight-pole HRHMB system.

5.2. Comparison of Equilibrium Current. The current waveforms of the twelve-pole HRHMB system and the eightpole HRHMB system are shown in Figures 11(a)-11(d). In the vertical direction, the maximum current of the twelvepole HRHMB system in the floating state is $1.8 \times 10^{-6} \mathrm{~A}$. The equilibrium current is $1 \times 10^{-6} \mathrm{~A}$, which is about $1 / 25$ of the eight-pole HRHMB system. Meanwhile, the maximum current in the horizontal direction of the twelve-pole HRHMB is $1.81 \times 10^{-6} \mathrm{~A}$, and the balance current is only $1 /$ 70 of the eight-pole HRHMB system. According to the simulation results, the twelve-pole HRHMB structure has lower power consumption than the eight-pole HRHMB structure.

\section{Comparison of Structure Dynamic Stiffness in the Cosimulation of HRHMB System}

In Magnet-Simulink cosimulation, the rotor is stabilized in the equilibrium position under the current regulation of the PID controller. Then external impact force $F_{K}$ is applied to the rotor in the balanced state. The maximum distance the rotor deviates from the equilibrium position is also called the maximum overshoot $C$ max. In the stage of external force action, the ratio of external interference force to the maximum overshoot is used as the construction dynamic stiffness $K$ of the HRHMB [30,31]. Therefore, the construction dynamic stiffness $K$ can be calculated by

$$
K=\frac{F_{K}}{C \max } .
$$

6.1. Comparison of Suspension Characteristics. The results are shown in Figures 12(a) and 12(b). At $0.3 \mathrm{~s}$, a vertical impact force of $5 \mathrm{~N}-25 \mathrm{~N}$ is applied to the rotor suspended in the equilibrium position. The maximum overshoot of the twelve-pole HRHMB system is $9.327 \times 10^{-6} \mathrm{~m}$, which is reduced by $6.78 \times 10^{-6} \mathrm{~m}$ compared with the maximum overshoot of the eight-pole HRHMB system. In addition, the twelve-pole HRHMB system returns to the equilibrium position and remained in stable suspension at $0.22 \mathrm{~s}$ after the impact. Besides the adjustment time was only $14.28 \%$ of the eight-pole HRHMB system.

The horizontal impact simulation is shown in Figures $12(\mathrm{c})$ and $12(\mathrm{~d})$. The maximum overshoot and adjustment time of the twelve-pole HRHMB system were $52.07 \%$ and $4 \%$ of the eight-pole HRHMB system, respectively. Therefore, the above simulation results show that the suspension characteristics of the twelve-pole HRHMB structure are better than that of the eight-pole HRHMB system. 


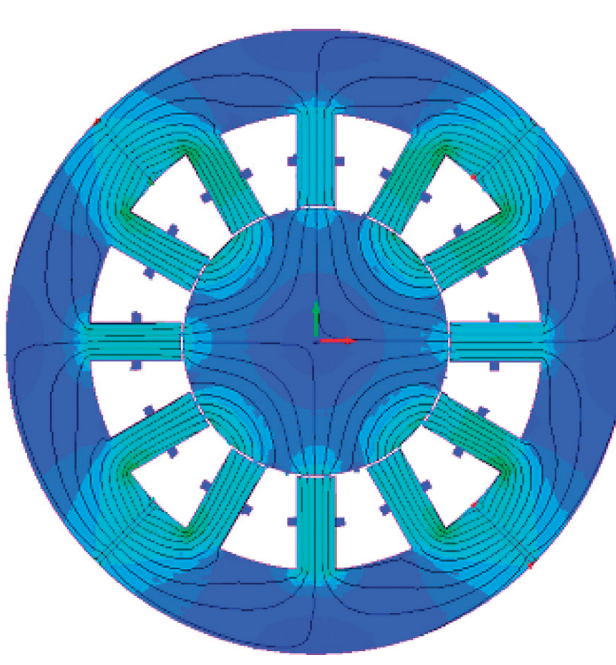

(a)
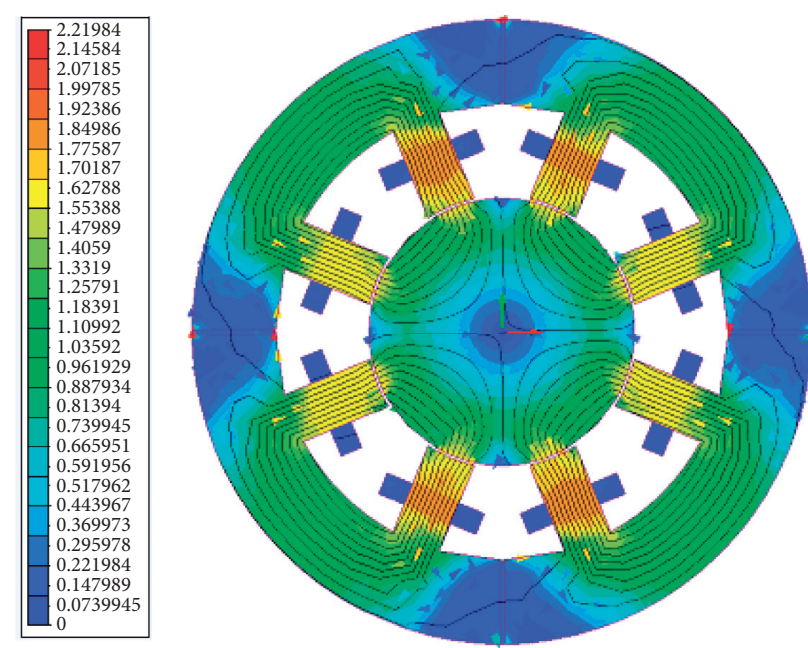

(b)

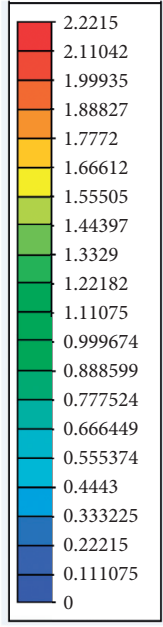

FIGURE 10: The flux density distribution of the stable suspension HRHMB. (a) The flux density distribution of the twelve-pole HRHMB. (b) The flux density distribution of the eight-pole HRHMB.

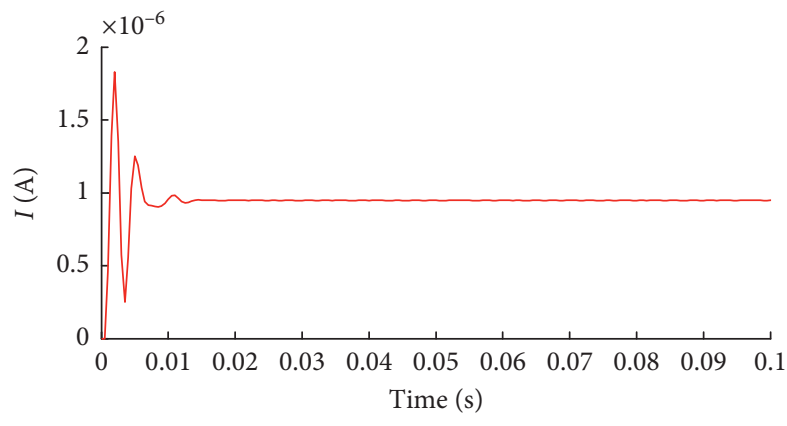

(a)

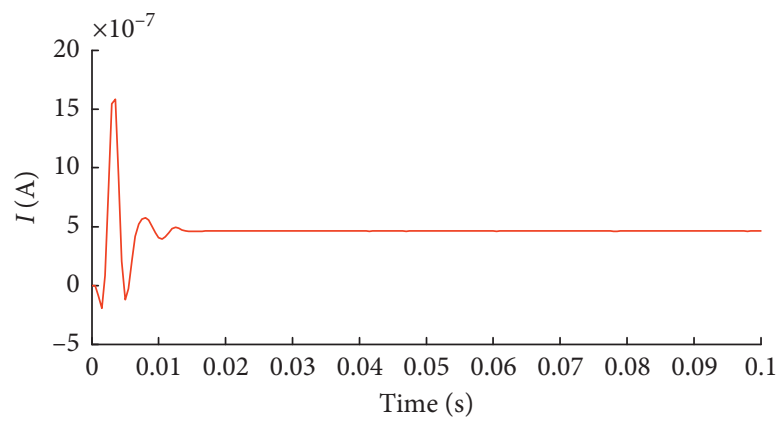

(c)

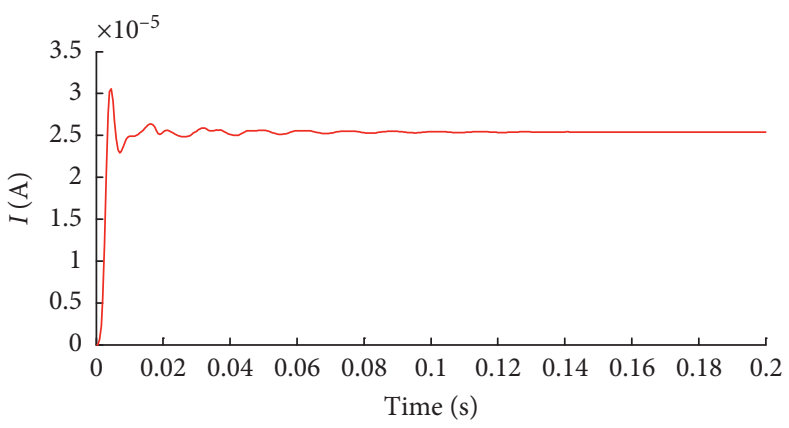

(b)

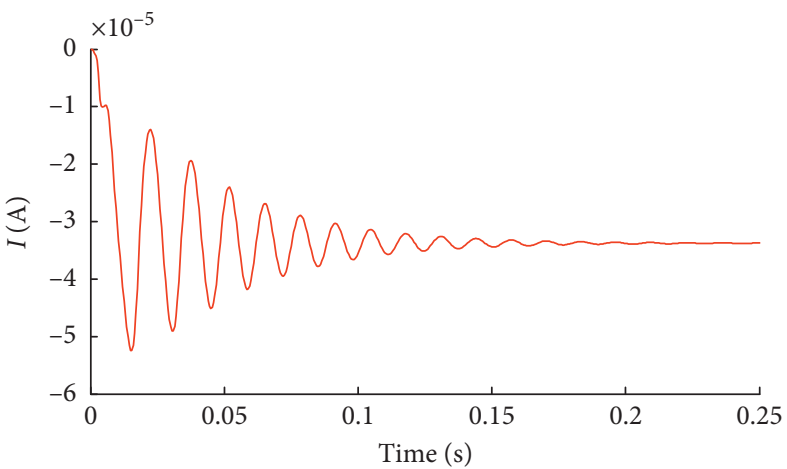

(d)

FIgURE 11: Radial current response of (a) the twelve-pole HRHMB system and (b) the eight-pole HRHMB system in the vertical direction. Radial current response of (c) the twelve-pole HRHMB system and (d) the eight-pole HRHMB system in the horizontal direction.

6.2. Comparison of Structures Dynamic Stiffness. The comparison of construction dynamic stiffness between the twelvepole HRHMB system and the eight-pole HRHMB system is shown in Figures 13(a) and 13(b). Under the same impact force, the construction dynamic stiffness of the twelve-pole HRHMB is better than the eight-pole HRHMB in both horizontal and vertical directions. Due to the unbalanced force of the eight-pole HRHMB, the horizontal bearing capacity is weakened, which seriously affects the dynamic stiffness of the structure in the horizontal direction. The construction dynamic stiffness of the eight-pole HRHMB is only $56.5 \%$ of the twelve-pole HRHMB structure. The simulation results show that the twelve-pole HRHMB has better suspension characteristics than the eight-pole HRHMB. 


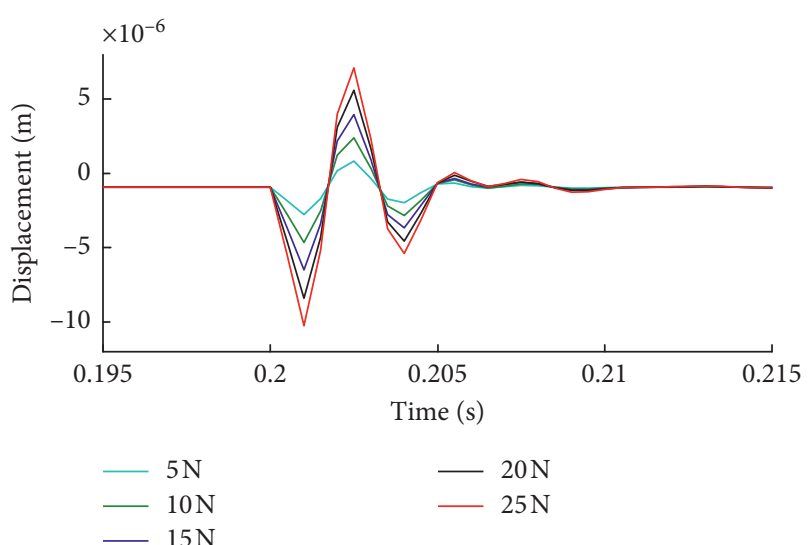

(a)

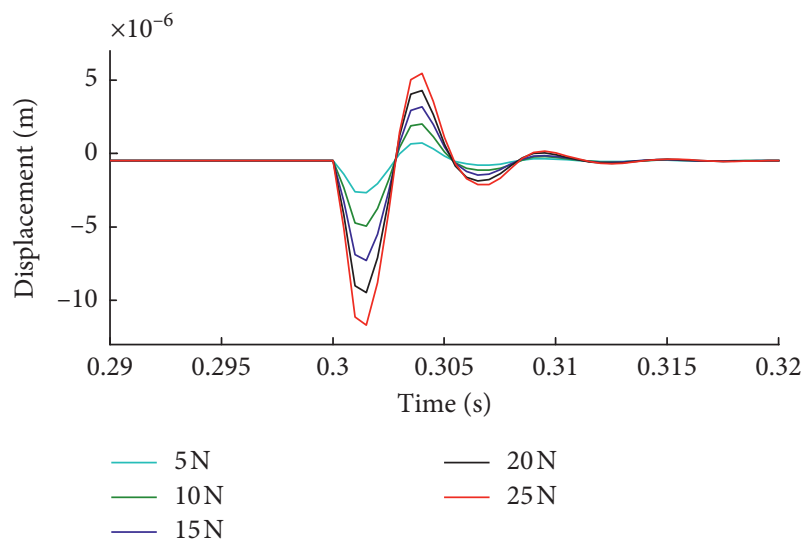

(c)

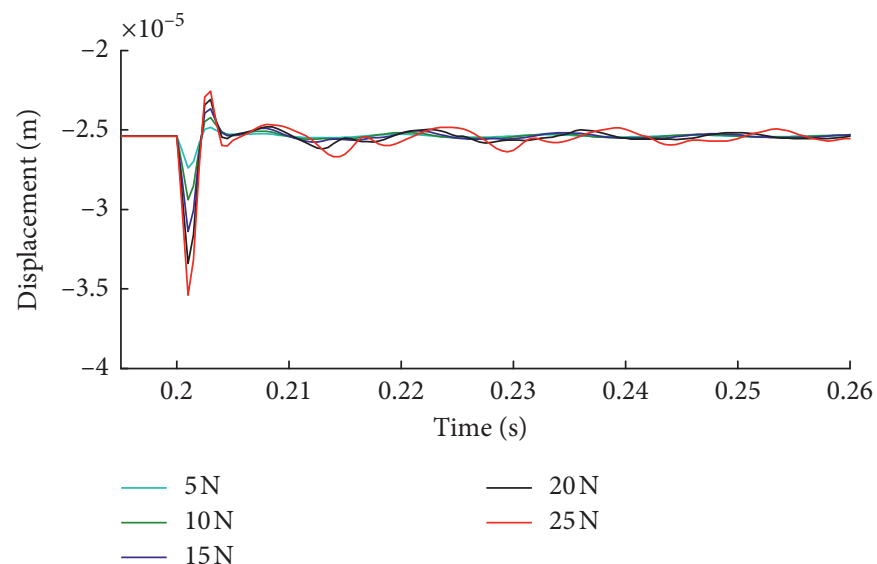

(b)

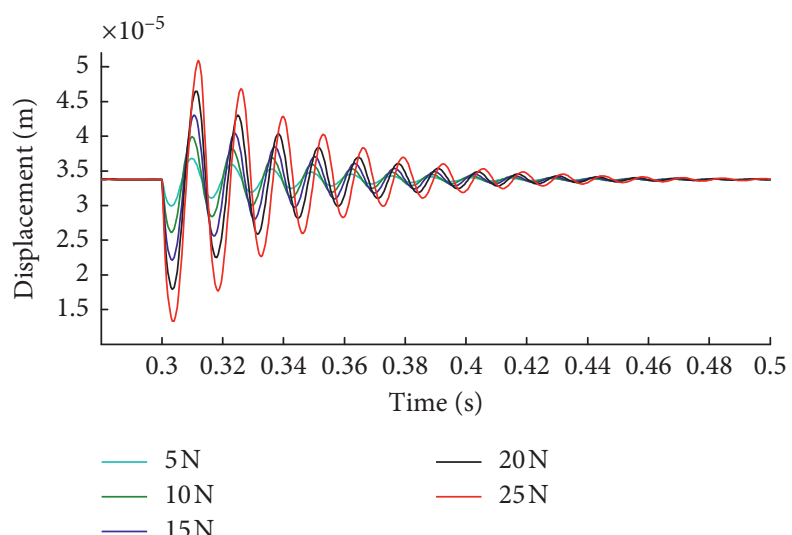

(d)

Figure 12: Radial shock response of HRHMB system. (a) The twelve-pole HRHMB system is subjected to vertical shock response. (b) The eight-pole HRHMB system is subjected to vertical shock response. (c) The twelve-pole HRHMB system is subjected to horizontal shock response. (d) The eight-pole HRHMB system is subjected to horizontal shock response.

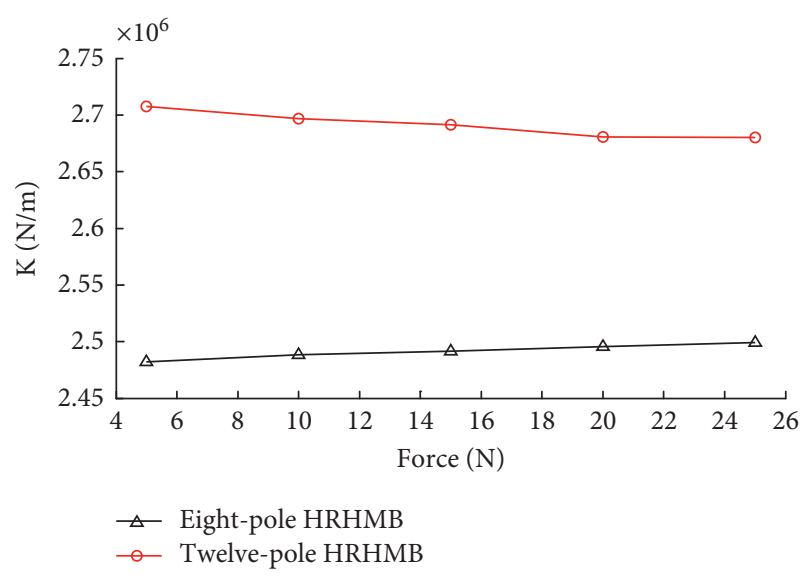

(a)

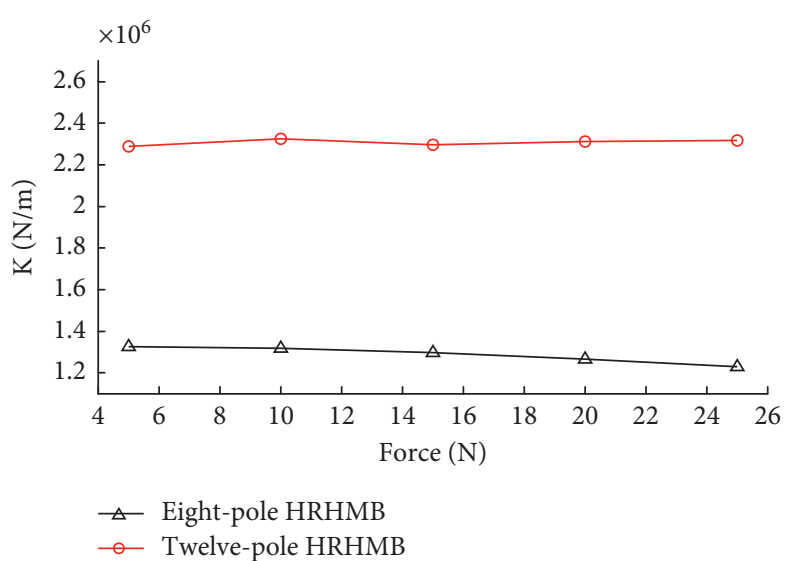

(b)

FIGURE 13: Comparison diagram of dynamic stiffness between the twelve-pole HRHMB system and the eight-pole HRHMB system. (a) Comparison of dynamic stiffness in the vertical direction. (b) Comparison of dynamic stiffness in the parallel direction. 


\section{Conclusions}

This paper proposes a twelve-pole HRHMB structure. By using the EMC method, the FEM and the Magnet-Simulink cosimulation method, the maximum bearing capacity, coupling, suspension characteristics, power consumption, and construction dynamic stiffness of the twelve-pole HRHMB are analyzed. And some positive conclusions are drawn as follows:

(1) The results of EMC method shows that the maximum radial load capacity of the twelve-pole HRHMB is $87.8 \mathrm{~N}$ under the coil current of $5 \mathrm{~A}$. And the maximum radial bearing capacity is about 36 times the weight of the rotor core. Therefore, it is sufficient to support the stable suspension of the rotor.

(2) The results of FEM and Magnet-Simulink cosimulation show that the twelve-pole HRHMB has the advantages of low power consumption, small coupling, large construction dynamic stiffness, and better suspension characteristics than the eight-pole HRHMB.

\section{Data Availability}

All data are included in the paper.

\section{Conflicts of Interest}

The authors declare that they have no conflicts of interest.

\section{Acknowledgments}

This work was sponsored by the National Natural Science Foundation of China (51565009) and the Natural Science Foundation of Guangxi Province (2015GXNSFAA139272).

\section{References}

[1] H. Zhu and S. Wang, "Electromagnetic characteristics analysis and experiment study of six-pole radial-axial active magnetic bearing," Proceedings of the CSEE, vol. 40, no. 5, pp. 1653$1663,2020$.

[2] X. Ren, J. Sun, C. Peng, and H. Qiao, "Analysis and design method of a combined radial-axial magnetic bearing based on asymmetric factor," IET Electric Power Applications, vol. 13, no. 5, pp. 686-693, 2019.

[3] T. Matsuzaki, M. Takemoto, S. Ogasawara, S. Ota, K. Oi, and D. Matsuhashi, "Novel structure of three-Axis Activecontrol-type magnetic bearing for reducing rotor iron loss," Institute of Electrical and Electronics Engineers Transactions on Magnetics, vol. 52, no. 7, pp. 1-4, 2016.

[4] X. Li and P. Alan, "Multi-input-multi-output control of a utility-scale, shaftless energy storage flywheel with a fivedegrees-of-freedom combination magnetic bearing," Journal of Dynamic Systems, Measurement, and Control, vol. 140, no. 10, 2018.

[5] X. Sun, Z. Jin, L. Chen, and Z. Yang, "Disturbance rejection based on iterative learning control with extended state observer for a four-degree-of-freedom hybrid magnetic bearing system," Mechanical Systems and Signal Processing, vol. 153, pp. 107465-107480, 2021.

[6] X. Li, B. Anvari, A. Palazzolo, Z. Wang, and H. Toliyat, "A utility-scale flywheel energy storage system with a shaftless, hubless, high-strength steel rotor," Institute of Electrical and Electronics Engineers Transactions on Industrial Electronics, vol. 65, no. 8, pp. 6667-6675, 2018.

[7] G. Chen, L. Yao, R. Zheng, L. Zhang, and J. Ding, "Design and implementation of a novel passive magnetically levitated nutation blood pump for the ventricular-assist device," Institute of Electrical and Electronics Engineers Access, vol. 7, pp. 169327-169337, 2019.

[8] B. Dong, K. Wang, B. Han et al., "High-speed maglev blower turbine locking device design analysis and experiment research," Journal of Mechanical Engineering, vol. 55, no. 3, pp. 154-161, 2019.

[9] B. Han, Z. Huang, and Y. Le, "Design aspects of a large scale turbomolecular pump with active magnetic bearings," Vacuum, vol. 142, pp. 96-105, 2017.

[10] T. Tezuka, N. Kurita, and T. Ishikawa, "Design and simulation of a five degrees of freedom active control magnetic levitated motor," Institute of Electrical and Electronics Engineers Transactions on Magnetics, vol. 49, no. 5, pp. 2257-2262, 2013.

[11] B. Han and S. Zheng, "Modeling and analysis of coupling performance of dynamic stiffness models for a novel combined radial-axial hybrid magnetic bearing," Mathematical Problems in Engineering, vol. 2014, 2014.

[12] Ji Li, L. Xu, and C. Jin, "Research on six magnetic Poles heteropolar radial permanent magnet biased magnetic bearing," China Mechanical Engineering, vol. 24, no. 6, pp. 730-735+741, 2013.

[13] J. Sun, J. Fang, X. Wang et al., "A new permanent magnet biased radial magnetic bearing," Transactions of China Electrotechnical Society, vol. 24, no. 11, pp. 53-60, 2009.

[14] A. Kenny, Nonlinear Electromagnetic Effects on Magnetic Bearing Performance and Power Loss, Ph.D. dissertation, Texas A\&M University, CollegeStation, TX, USA, 2001.

[15] X. Zhao, Z. Deng, and B. Wang, "Parameter design and realization of permanent magnet biased heterploar radial magnetic bearing," Transactions of China Electrotechnical Society, vol. 2012, no. 7, pp. 131-138+159, 2012.

[16] C. Jin, D. Lv, X. Yan, Y. Xu, F. Xiong, and L. Xu, "A novel eight-pole heteropolar radial-axial hybrid magnetic bearing," International Journal of Applied Electromagnetics and Mechanics, vol. 60, no. 3, pp. 423-444, 2019.

[17] R. Zhu, W. Xu, C. Ye, J. Zhu, G. Lei, and X. Li, "Design optimization of a novel heteropolar radial hybrid magnetic bearing using magnetic circuit model," Institute of Electrical and Electronics Engineers Transactions on Magnetics, vol. 54, no. 3, pp. 1-5, 2018.

[18] Y. Zhong, L. Wu, X. Huang, and Y. Fang, "Modeling and design of a 3-DOF magnetic bearing with toroidal radial control coils," Institute of Electrical and Electronics Engineers Transactions on Magnetics, vol. 55, no. 7, pp. 1-7, 2019.

[19] X. Sun, B. Su, L. Chen, Z. Yang, X. Xu, and Z. Shi, "Precise control of a four degree-of-freedom permanent magnet biased active magnetic bearing system in a magnetically suspended direct-driven spindle using neural network inverse scheme," Mechanical Systems and Signal Processing, vol. 88, pp. 36-48, 2017.

[20] Z. Jin, X. Sun, Y. Cai, J. Zhu, G. Lei, and Y. Guo, "Comprehensive sensitivity and cross-factor variance analysisbased multi-objective design optimization of a 3-DOF hybrid 
magnetic bearing," Institute of Electrical and Electronics Engineers Transactions on Magnetics, vol. 57, no. 2, pp. 1-4, 2021.

[21] A. Yamauchi and O. Kuwahara, "Composite-type electromagnet and radial magnetic bearing," vol. 6, p. 563, 2003 U.S. Patent.

[22] J. Tang, J. Sun, J. Fang, and G. Shuzhi Sam, "Low eddy loss axial hybrid magnetic bearing with gimballing control ability for momentum flywheel," Journal of Magnetism and Magnetic Materials, vol. 329, pp. 153-164, 2013.

[23] J. Sun, H. Zhou, X. Ma, and Z. Ju, "Study on PID tuning strategy based on dynamic stiffness for radial active magnetic bearing," ISA Transactions, vol. 80, no. 37, pp. 458-474, 2018.

[24] S. Xu and J. Fang, "A novel conical active magnetic bearing with claw structure," Institute of Electrical and Electronics Engineers Transactions on Magnetics, vol. 50, no. 5, pp. 1-8, 2014.

[25] Q. Ding, X. Wang, and Z. Deng, "Design and comparison of radial force winding configurations for wide air-gap fluxswitching bearingless permanent-magnet motor," Transactions of China Electrotechnical Society, vol. 33, no. 11, pp. 2403-2413, 2018.

[26] H. Zhu, S. Ding, and J. Jv, "Modeling for three-Pole radial hybrid magnetic bearing considering edge effect," Energies, vol. 9, no. 345, 2016.

[27] Z. Yin, Y. Cai, B. Liu, W. Wang, and X. Chen, "Application of spherical magnetic bearing in magnetically suspended control and sensitive gyro," Mathematical Problems in Engineering, vol. 2020, Article ID 7698794, 11 pages, 2020.

[28] Qi Zhao, W. Guo, and J. Wang, "A control method of electromagnetic levitation system with the Co-simulation of simulink and magnet," Small \& Special Electrical Machines, vol. 9, pp. 42-45+55, 2008.

[29] Y. Duan, Z. Zhong, Z. Cai, and Y. Qi, "Co-simulation of Magnet and Simulink for radial electromagnetic levitation system," Journal of Guilin University of Technology, vol. 2020, pp. 1-8, 2020.

[30] J. Zhao, Y. Zhou, and Z. Shi, "Automatic measurement of stiffness and damping of active magnetic bearings," Journal of Mechanical Engineering, vol. 46, no. 20, pp. 48-52, 2010.

[31] X. Liu, Y. Hu, W. Zhang, and W. Jian, "Measuring experiments on construction static and dynamic stiffness of magnetic suspension system," Journal of Mechanical Engineering, vol. 21, no. 8, pp. 908-912, 2010. 